\title{
Comparative transcriptome analysis reveals the transcriptional alterations in heat- resistant and heat-sensitive sweet maize (Zea mays L.) varieties under heat stress
}

Jiang Shi ${ }^{1}$, Baiyuan Yan ${ }^{3}$, Xuping Lou ${ }^{4}$, Huasheng Ma ${ }^{1 *}$ and Songlin Ruan ${ }^{1,2^{*}}$

\begin{abstract}
Background: Despite the heat-related physiology and heat-shock proteins in maize have been extensively studied, little is known about the transcriptome profiling of how the maize varieties with different genotypes responding to high temperatures. Seedling mortality of Xiantian 5 (XT) is significantly lower than that of Zhefengtian (ZF) when exposed to high temperature $\left(42^{\circ} \mathrm{C}\right.$ for $6 \mathrm{~h}$ ) and followed by a recovery growth $\left(25^{\circ} \mathrm{C}\right.$ for one week). Therefore, we performed a transcriptome analysis using the total RNA extracted from the leaves of XT and ZF that were previously subjected to heat stress at $42{ }^{\circ} \mathrm{C}$ for $0 \mathrm{~h}, 0.5 \mathrm{~h}$, and $3 \mathrm{~h}$, respectively.
\end{abstract}

Results: A total of 516 commonly up-regulated and 1,261 commonly down-regulated genes were identified among XT/ZF, XT0.5/ZF0.5 and XT3/ZF3 using transcriptome analysis. Gene Ontology classification of the 516 up-regulated genes showed that their encoded proteins were significantly assigned to 18 cellular components, and were classified into 9 functional categories, and were involved in 9 biological processes. Most of proteins encoded by up-regulated genes were localized in chloroplast and its structural components, and involved in multiple biological processes associated with photosynthesis, indicating that these chloroplast proteins play an important role in increasing heat tolerance in sweet maize. While the proteins encoded by 1,261 down-regulated genes were significantly assigned to 31 cellular components, and were classified into 3 functional categories, and were involved in 9 biological processes. Interestingly, these proteins were involved in a series of biological processes from gene expression to translation, suggesting that lowering these processes may contribute to improved heat resistance in sweet maize. The up-regulated genes were identified to be involved in 36 distinct metabolic pathways, of which the most significant ones was secondary metabolite biosynthetic pathway. While the down-regulated genes were identified to be involved in 23 distinct metabolic pathways, of which the most significant ones were found in ribosome. Quantitative real-time PCR analysis demonstrated that 5 genes involved in the biosynthesis of secondary metabolites and photosynthesis in XT have higher abundance than those in ZF, whereas 5 ribosome genes in XT showed lower abundance than those in ZF. In addition, heat-tolerant sweet maize may keep at lower growth level than heat-sensitive one through dowregulating expression of genes related to zeatin and brassinosteroid biosynthesis to better regulate heat stress responses.

Conclusions: Comparative transcriptomic profiling reveals transcriptional alterations in heat-resistant and heat-sensitive sweet maize varieties under heat stress, which provides a new insight into underlying molecular mechanism of maize in response to heat stress.

Keywords: Sweet maize, Heat-resistance, Transcriptome profiling, Gene Ontology, Pathway analysis

\footnotetext{
*Correspondence: hzhsma@163.com; ruansl1@hotmail.com

${ }^{1}$ Institute of Crop Science, Hangzhou Academy of Agricultural Sciences,

Hangzhou 310024, People's Republic of China

Full list of author information is available at the end of the article
} 


\section{Background}

Maize originates from the highlands of Central and South America's tropical and subtropical regions and is adapted to warm temperatures [1]. Although climatic factors, such as light, temperature, water, and $\mathrm{CO}_{2}$ in air, all have significant influences on maize production, temperature is still the major factor affecting maize growth and development [1]. In recent years, with the increasing and frequent occurrence of extremely high temperatures due to global warming, high temperature has become one of the most important abiotic stresses restricting crop production worldwide [2]. Heat stress affects maize flowering, pollination, and grain filling, which then results in the decline of seed setting rate and thus reduces maize production [1]. Therefore, the adverse effect of high temperatures on maize production is increasingly becoming a concern.

Maize seedlings grown under high temperatures for long durations will have thin leaf morphology, and their leaf colors gradually change from green to light green, and eventually become yellow. Heat stress can cause the reductions in leaf extension rate, shoot biomass, and $\mathrm{CO}_{2}$ assimilation rate [3]. High temperature during the flowering stage can lead to reduced pollen quality, low yield, and poor quality of the final products [1]. Further research shows that heat stress can affect grain crude protein, crude fat, and lysine contents, which in turn leads to the low quality of maize products [4]. In addition, heat-resistant maize variety maintains higher levels of chlorophyll content, photosystem II electron transfer rate, photosynthetic rate, and other important physical characteristics under heat stress [4].

The molecular mechanisms underlying plant heat tolerance including the alteration of signaling cascades and transcriptional control, increasing production of antioxidants $[5,6]$ and osmoprotectants, and the expression of heat shock proteins [7], have been presented. Heat shock proteins (HSPs) are a type of proteins with highly conserved amino acid sequences and functions. HSPs function as molecular chaperones and are involved in repairing and refolding damaged proteins as well as synthesizing, folding and transporting normal proteins [8]. Extensive studies have demonstrated the notable protection of HSP70, HSP101 and smHSPs family proteins from heat stress.

Transcriptomics is a powerful tool for discovering differentially expressed genes and has been widely applied in some crop species, including rice [9-12], maize [13], wheat [14], barley [15], cotton [16, 17], rape [18], potato [19], tea [20], tomato [21], pepper [22], watermelon [23], Phaseolus vulgaris [24], Vigna mungo [24], pea [25], chickpea [26] and citrus fruit [27]. Among them, the transcriptome profiling of rice $[9,10]$, barley [15], pepper [22] and maize [28] in response to heat stress has been performed. However, comparative transcriptome analysis has only been performed in rice and pepper between heat-resistant and heat-sensitive cultivars. In this study, to detect the differential gene expression in different maize genotypes under heat stress, heatresistant and heat-sensitive maize seedlings were treated at $42{ }^{\circ} \mathrm{C}$, and the expression of genes in leaves collected at different time points was measured. A comparative transcriptomic analysis was performed to reveal the significantly up-regulated and down-regulated genes. Gene Ontology (GO) classification of the proteins encoded by these genes was used to analyze their cellular locations. A pathway analysis was performed to reveal the biological pathways involving these genes. This study may provide a new insight into the transcriptional alterations in heat-resistant and heat-sensitive sweet maize varieties responding to heat stress.

\section{Results}

Responses of maize seedlings with different genotypes to heat stress

Maize varieties XT (heat-resistant) and ZF (heat-sensitive) were treated with the high temperature of $42{ }^{\circ} \mathrm{C}$, followed by one week of recovery growth at $25{ }^{\circ} \mathrm{C}$. As shown in Fig. 1, the seedling mortality of XT was significantly lower than that of $\mathrm{ZF}$, indicating that $\mathrm{XT}$ is more resistant to heat stress.

\section{Gene expression profiles of different maize genotypes in response to heat stress}

As shown in Fig. 2a, different from the heat sensitive variety $\mathrm{ZF}$, the maize variety XT (heat-resistant) showed an increased number of differentially expressed genes under different durations of heat treatment $(0,0.5 \mathrm{~h}$ or $3 \mathrm{~h}$ ), including both up-regulated and down-regulated genes. The differential expression analysis of XT/ZF, XT0.5/ZF0.5 and XT3/ZF3 identified 516 commonly upregulated and 1,261 commonly down-regulated genes (Fig.2b and c). In addition, the number of uniquely upregulated or down-regulated genes between XT/ZF, XT0.5/ZF0.5 or XT3/ZF3 was increased with increasing duration of heat treatment. There were 766,812 , and 1,172 down-regulated genes, and 1,429, 1,639, and 2,285 up-regulated genes, respectively (Fig.2b and c).

\section{GO classification of common differential genes}

We then performed a GO classification of 516 upregulated genes, and the results showed that the proteins encoded by these genes were significantly assigned to 18 cellular components including thylakoid part (GO: 0044436), photosynthetic membrane (GO: 0034357), chloroplast thylakoid (GO: 0009534), plastid thylakoid (GO: 0031976), thylakoid membrane (GO: 0042651), thylakoid (GO: 0009579), organelle subcompartment (GO: 0031984), plastid thylakoid membrane (GO: 


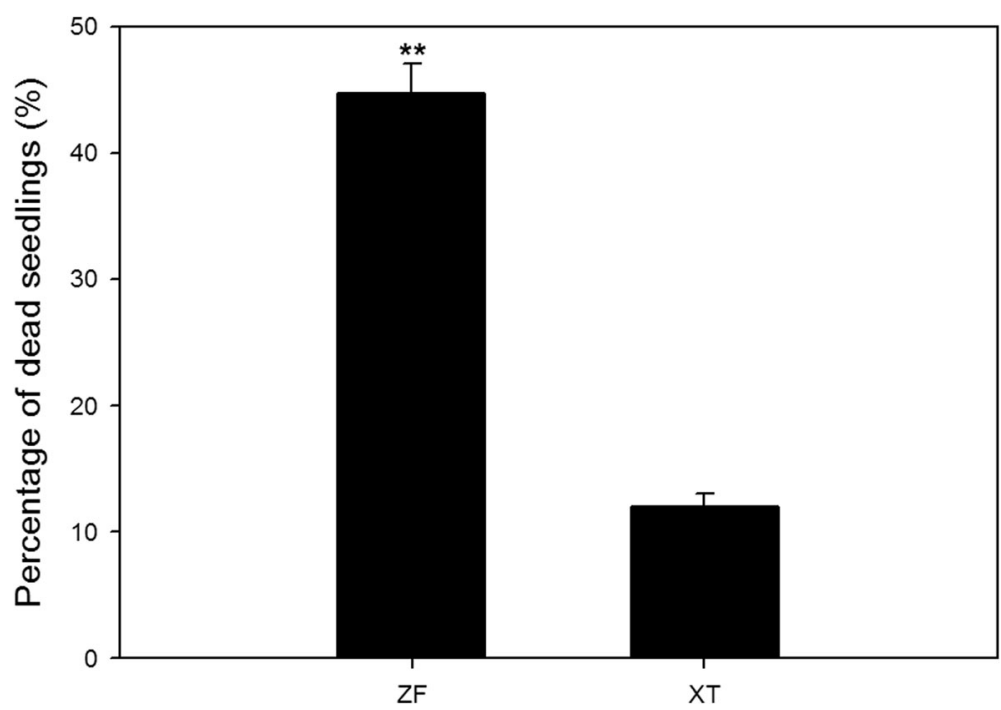

Fig. 1 Mortality of maize seedlings of different genotypes under heat stress. Maize varieties XT (heat-resistant) and ZF (heat-sensitive) were treated at $42{ }^{\circ} \mathrm{C}$ for $6 \mathrm{~h}$, followed by recovery growth at $25^{\circ} \mathrm{C}$ for one week. Three independent experimental replicates were analyzed for each sample, and data were indicated as mean \pm SE $(n=3)$. XT: Xiantian 5; ZF: Zhefengtian 2
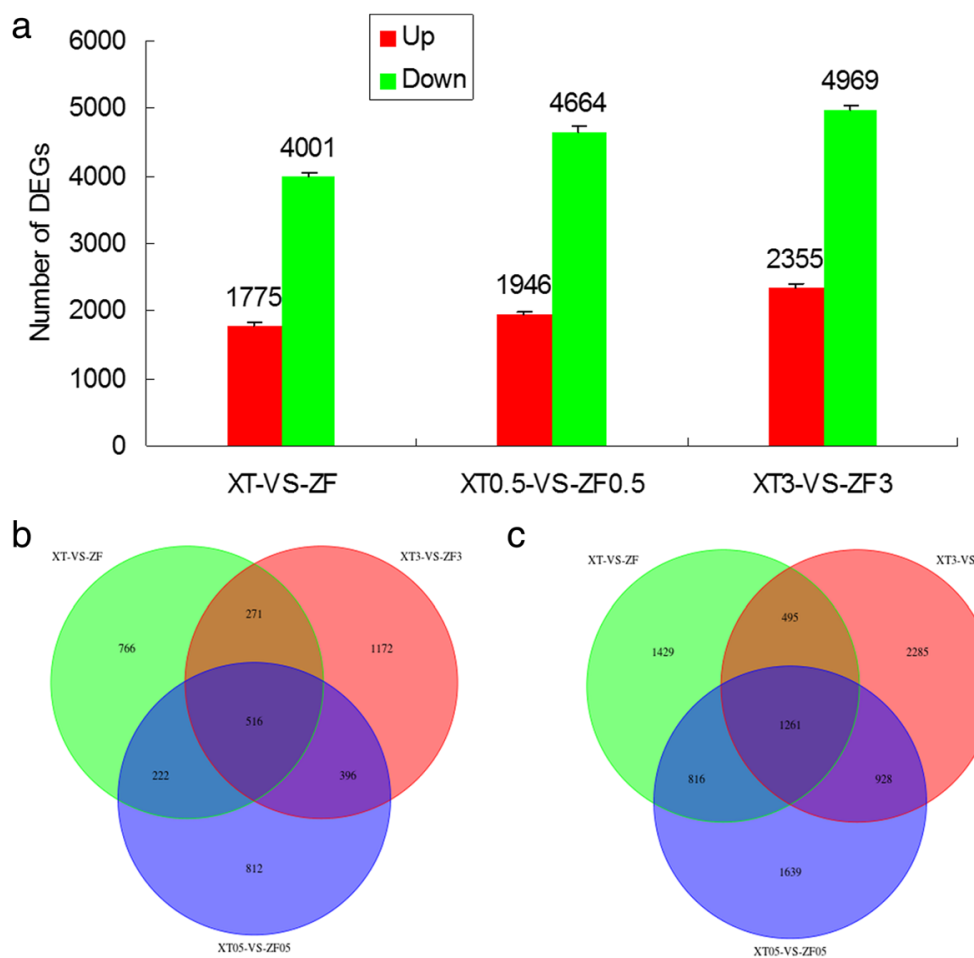

C

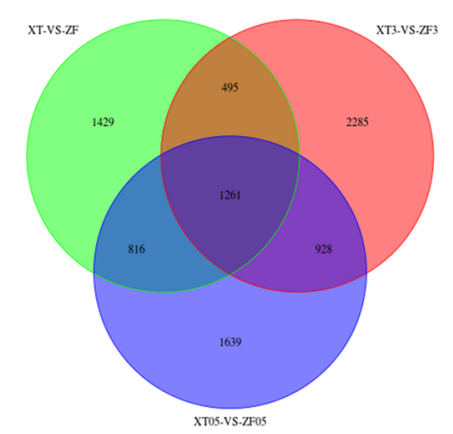

Fig. 2 Gene expression profile of different maize genotypes in response to heat stress. a The total number of up-regulated and down-regulated genes. b Venn diagram of up-regulated genes. c Venn diagram of down-regulated genes. Three independent experimental replicates were analyzed for each sample, and data were indicated as mean \pm SE $(n=3)$. XT: Xiantian 5; ZF: Zhefengtian 2. XT-ZF, XT0.5 -ZF0.5 and XT3-ZF3 represent XT-ZF seedlings treated at $42^{\circ} \mathrm{C}$ for $0,0.5,3 \mathrm{~h}$, respectively 
0055035), plastid part (GO: 0044435), thylakoid lumen (GO: 0031977), chloroplast thylakoid membrane (GO: 0009535), photosystem (GO: 0009521), chloroplast part (GO: 0044434), chloroplast (GO: 0009507), photosystem II (GO: 0009523), plastid (GO: 0009536), photosystem I (GO: 0009522) and envelope (GO: 0031975) (Table 1). Subsequently, proteins encoded by the up-regulated genes were classified into 9 functional categories, including 50 proteins with oxidoreductase activity (GO: 0016491), 6 proteins with peptidase inhibitor activity (GO: 0030414), 6 proteins with peptidase regulator activity (GO: 0061134), 18 proteins with tetrapyrrole binding (GO: 0046906), 4 proteins with inositol-1,3,4trisphosphate 6-kinase activity (GO: 0052725), 4 proteins with inositol tetrakisphosphate kinase activity (GO: 0051765), 4 proteins with inositol trisphosphate kinase activity (GO: 0051766), 16 proteins with heme binding (GO: 0020037) and 2 proteins with omega-3 fatty acid desaturase activity (GO: 0042389) (Table 1). Finally, they were assigned to be mainly involved in 9 biological processes, photosynthesis (GO: 0015979), oxidationreduction process (GO: 0055114), photosynthesis, light reaction (GO: 0019684), negative regulation of peptidase activity (GO: 0010466), regulation of peptidase activity (GO: 0052547), negative regulation of hydrolase activity (GO: 0051346), regulation of proteolysis (GO: 0030162), regulation of protein processing (GO: 0070613) and regulation of protein metabolic process (GO: 0051246) (Table 1).

Similarly, we performed a GO classification of 1,261 commonly down-regulated genes, and discovered that the proteins encoded by these genes were significantly assigned to 31 cellular components, including ribosomal subunit (GO: 0044391), cytosolic ribosome (GO: 0022626), cytosolic part (GO: 0044445), ribosome (GO: 0005840), ribonucleoprotein complex (GO: 0030529), cytosolic large ribosomal subunit (GO: 0022625), large ribosomal subunit (GO: 0015934), nucleolus (GO: 0005730), cytosol (GO: 0005829), membrane-enclosed lumen (GO: 0031974), cytosolic small ribosomal subunit (GO: 0022627), organelle lumen (GO: 0043233), intracellular organelle lumen (GO: 0070013), small ribosomal subunit (GO: 0015935), nuclear lumen (GO: 0031981), non-membrane-bounded organelle (GO: 0043228), intracellular non-membrane-bounded organelle (GO: 0043232), nuclear part (GO: 0044428), intracellular organelle part (GO: 0044446), organelle part (GO: 0044422), vacuolar membrane (GO: 0005774), vacuolar part (GO: 0044437), cytoplasm (GO: 0005737), chloroplast (GO: 0009507), cell-cell junction (GO: 0005911), plasmodesma (GO: 0009506), cell junction (GO: 0030054), symplast (GO: 0055044), vacuole (GO: 0005773), macromolecular complex (GO: 0032991) and cytoplasmic part (GO: 0044444) (Table 2). Next, proteins encoded by the down-regulated genes were classified into 3 functional categories, including 66 proteins with structural constituent of ribosome (GO: 0003735), 70 proteins structural molecule activity (GO: 0005198) and 3 proteins with glutamate-cysteine ligase activity (GO: 0004357) (Table 2). Finally, they were assigned to be involved in 14 biological processes, including translation (GO: 0006412), gene expression (GO: 0010467), cellular macromolecule biosynthetic process (GO: 0034645), macromolecule biosynthetic process (GO: 0009059), cellular biosynthetic process (GO: 0044249), biosynthetic process (GO: 0009058), organic substance biosynthetic process (GO: 1901576), ribosome biogenesis (GO: 0042254), metabolic process (GO: 0042254), ribonucleoprotein complex biogenesis (GO: 0022613), polysaccharide localization (GO: 0033037), callose localization (GO: 0052545), sulfur compound metabolic process (GO: 0006790) and defense response by callose deposition (GO: 0052542) (Table 2).

\section{Pathway analysis of common differential genes}

To determine the involvement of these differentially expressed genes in heat resistance, we performed a pathway analysis to identify the potential target genes (Fig. 3). The up-regulated genes have been identified to be involved in 36 distinct metabolic pathways, including biosynthesis of secondary metabolites, metabolic pathway, fatty acid metabolism, microbial metabolism in diverse environments, photosynthesis, photosynthesis - antenna proteins, ascorbate and aldarate metabolism, retinol metabolism, glycerolipid metabolism, drug metabolism cytochrome P450, tryptophan metabolism, one carbon pool by folate, benzoxazinoid biosynthesis, diterpenoid biosynthesis, methane metabolism, two-component system, stilbenoid, diarylheptanoid and gingerol biosynthesis, metabolism of xenobiotics by cytochrome P450, flavonoid biosynthesis, biosynthesis of unsaturated fatty acids, glycolysis/gluconeogenesis, glycine, serine and threonine metabolism, ubiquinone and other terpenoidquinone biosynthesis, carbon fixation in photosynthetic organisms, biosynthesis of ansamycins, propanoate metabolism, glyoxylate and dicarboxylate metabolism, pyruvate metabolism, polycyclic aromatic hydrocarbon degradation, chlorocyclohexane and chlorobenzene degradation, alphaLinolenic acid metabolism, and bisphenol degradation (Fig. 3a). Among them, the most significant ones were secondary metabolite biosynthetic pathway, followed by the metabolic pathway. In addition, some other pathways were involved in photosynthesis. While the downregulated genes have been identified to be involved in 23 distinct metabolic pathways, including ribosome, zeatin biosynthesis, biosynthesis of secondary metabolites, phenylpropanoid biosynthesis, spliceosome, cytosolic DNA-sensing pathway, glutathione metabolism, sesquiterpenoid and triterpenoid biosynthesis, terpenoid backbone biosynthesis, alpha-Linolenic acid metabolism, mismatch repair, 
Table 1 GO classification of common up-regulated genes in both XT and ZF

\begin{tabular}{|c|c|c|}
\hline Gene Ontology term & $\begin{array}{l}\text { The number } \\
\text { of Genes }\end{array}$ & $\begin{array}{l}-\log _{10} \\
(P \text { value })^{*}\end{array}$ \\
\hline \multicolumn{3}{|l|}{ Cellular component } \\
\hline thylakoid part (GO: 0044436) & 26 & 9.16494 \\
\hline $\begin{array}{l}\text { photosynthetic membrane } \\
\text { (GO: 0034357) }\end{array}$ & 22 & 6.8697 \\
\hline $\begin{array}{l}\text { chloroplast thylakoid } \\
\text { (GO: 0009534) }\end{array}$ & 24 & 6.6383 \\
\hline $\begin{array}{l}\text { plastid thylakoid } \\
\text { (GO: 0031976) }\end{array}$ & 24 & 6.6253 \\
\hline $\begin{array}{l}\text { thylakoid membrane } \\
\text { (GO: 0042651) }\end{array}$ & 21 & 6.3925 \\
\hline Thylakoid (GO: 0009579) & 27 & 6.1649 \\
\hline $\begin{array}{l}\text { organelle subcompartment } \\
\text { (GO: 0031984) }\end{array}$ & 24 & 6.1524 \\
\hline $\begin{array}{l}\text { plastid thylakoid membrane } \\
\text { (GO: 0055035) }\end{array}$ & 19 & 5.4935 \\
\hline plastid part (GO: 0044435) & 47 & 5.3468 \\
\hline thylakoid lumen (GO: 0031977) & 10 & 5.1169 \\
\hline $\begin{array}{l}\text { chloroplast thylakoid membrane } \\
\text { (GO: 0009535) }\end{array}$ & 18 & 4.8125 \\
\hline photosystem (GO: 0009521) & 9 & 4.8125 \\
\hline chloroplast part (GO: 0044434) & 45 & 4.7011 \\
\hline chloroplast (GO: 0009507) & 67 & 4.1675 \\
\hline photosystem II (GO: 0009523) & 6 & 2.7447 \\
\hline plastid (GO: 0009536) & 98 & 2.6253 \\
\hline photosystem I (GO: 0009522) & 5 & 2.0477 \\
\hline envelope (GO: 0031975) & 4 & 1.3821 \\
\hline \multicolumn{3}{|l|}{ Molecular function } \\
\hline $\begin{array}{l}\text { oxidoreductase activity } \\
\text { (GO: 0016491) }\end{array}$ & 50 & 2.9031 \\
\hline $\begin{array}{l}\text { peptidase inhibitor activity } \\
\text { (GO: 0030414) }\end{array}$ & 6 & 2.7447 \\
\hline $\begin{array}{l}\text { peptidase regulator activity } \\
\text { (GO: 0061134) }\end{array}$ & 6 & 2.7447 \\
\hline $\begin{array}{l}\text { tetrapyrrole binding } \\
\text { (GO: 0046906) }\end{array}$ & 18 & 2.5031 \\
\hline $\begin{array}{l}\text { inositol-1,3,4-trisphosphate } \\
\text { 6-kinase activity (GO: 0052725) }\end{array}$ & 4 & 1.9119 \\
\hline $\begin{array}{l}\text { inositol tetrakisphosphate } \\
\text { kinase activity (GO: 0051765) }\end{array}$ & 4 & 1.7755 \\
\hline $\begin{array}{l}\text { inositol trisphosphate kinase } \\
\text { activity (GO: 0051766) }\end{array}$ & 4 & 1.7113 \\
\hline heme binding (GO: 0020037) & 16 & 1.600 \\
\hline $\begin{array}{l}\text { omega-3 fatty acid desaturase } \\
\text { activity (GO: 0042389) }\end{array}$ & 2 & 1.3372 \\
\hline \multicolumn{3}{|l|}{ Biological process } \\
\hline photosynthesis (GO: 0015979) & 16 & 4.0996 \\
\hline oxidation-reduction process & 57 & 3.7959 \\
\hline
\end{tabular}

Table $1 \mathrm{GO}$ classification of common up-regulated genes in both XT and ZF (Continued)

\begin{tabular}{lll}
\hline $\begin{array}{l}\text { photosynthesis, light reaction } \\
\text { (GO: } 0019684)\end{array}$ & 10 & 3.0132 \\
$\begin{array}{l}\text { negative regulation of peptidase } \\
\text { activity (GO: 0010466) }\end{array}$ & 6 & 2.3615 \\
$\begin{array}{l}\text { regulation of peptidase activity } \\
\text { (GO: } 0052547)\end{array}$ & 6 & 2.3615 \\
$\begin{array}{l}\text { negative regulation of hydrolase } \\
\text { activity (GO: 0051346) }\end{array}$ & 6 & 2.2660 \\
$\begin{array}{l}\text { regulation of proteolysis } \\
\text { (GO: } 0030162)\end{array}$ & 6 & 1.9618 \\
$\begin{array}{l}\text { regulation of protein processing } \\
\text { (GO: } 0070613)\end{array}$ & 6 & 1.96182 \\
$\begin{array}{l}\text { regulation of protein metabolic } \\
\text { process (GO: 0051246) }\end{array}$ & 15 & 1.3416 \\
\hline
\end{tabular}

${ }^{*} P$ values of all GO terms are lower than 0.05 . Conversely, $-\log _{10}(P$ value) values of all GO terms are greater than 1.3010 , that is, the greater $-\log _{10}$ ( $P$ value) value, the better significance

ribosome biogenesis in eukaryotes, phototransduction, linoleic acid metabolism, metabolism of xenobiotics by cytochrome P450, selenocompound metabolism, isoflavonoid biosynthesis, drug metabolism-cytochrome P450, olfactory transduction, homologous recombination, and brassinosteroid biosynthesis (Fig. 3b). Among them, the most significant ones were found in ribosome, and the other pathways were related to monoterpenoid biosynthesis and zeatin biosynthesis.

\section{Validation of differentially expressed candidate genes}

To validate the Illumina sequencing data and the expression patterns of the DEGs revealed by RNA-Seq, qRTPCR was performed to examine the expression patterns of 10 DEGs, including 5 genes involved in the biosynthesis of secondary metabolites and photosynthesis, and 5 ribosome genes (Fig. 4). qRT-PCR results showed that 5 genes involved in the biosynthesis of secondary metabolites and photosynthesis, including XM_008655452 (pyruvate decarboxylase 3-like), XM_008675504 (uncha racterized LOC103649793), XM_008680505 (psbQ-like protein 1, chloroplastic), XM_008677226 (chlorophyll ab binding protein of LHCII type 1-like) and NM 001154967 (chlorophyll a-b binding protein 2), in XT had higher abundance than those in ZF (Fig. 4a), while 5 ribosome genes, including NM_001139328 (60S ribosomal protein L32), NM_001136625 (60S ribosomal protein L7a), NM_001137336 (ribosomal protein L13A-like protein), NM_001175010 (Ribosomal protein L3) and XM_008671301 (60S ribosomal protein L37a) in XT showed lower abundance than those in ZF (Fig. 4c), which was consistent with the RNA-seq data from XT and ZF (Fig. 4b and d). 
Table 2 GO classification of common down-regulated genes in both XT and ZF

\begin{tabular}{|c|c|c|}
\hline Gene Ontology term & $\begin{array}{l}\text { The number } \\
\text { of Genes }\end{array}$ & $\begin{array}{l}-\log _{10} \\
(P \text { value })^{*}\end{array}$ \\
\hline \multicolumn{3}{|l|}{ Cellular component } \\
\hline ribosomal subunit (GO: 0044391) & 59 & 25.0200 \\
\hline cytosolic ribosome (GO: 0022626) & 67 & 23.1024 \\
\hline cytosolic part (GO: 0044445) & 69 & 21.3206 \\
\hline ribosome (GO: 0005840) & 77 & 20.5086 \\
\hline $\begin{array}{l}\text { ribonucleoprotein complex } \\
\text { (GO: 0030529) }\end{array}$ & 91 & 19.3747 \\
\hline $\begin{array}{l}\text { cytosolic large ribosomal subunit } \\
\text { (GO: 0022625) }\end{array}$ & 34 & 14.6536 \\
\hline large ribosomal subunit (GO: 0015934) & 34 & 13.6498 \\
\hline nucleolus (GO: 0005730) & 65 & 12.4437 \\
\hline cytosol (GO: 0005829) & 157 & 10.3215 \\
\hline $\begin{array}{l}\text { membrane-enclosed lumen } \\
\text { (GO: 0031974) }\end{array}$ & 88 & 10.2774 \\
\hline $\begin{array}{l}\text { cytosolic small ribosomal subunit } \\
\text { (GO: 0022627) }\end{array}$ & 24 & 9.7670 \\
\hline organelle lumen (GO: 0043233) & 86 & 9.6556 \\
\hline $\begin{array}{l}\text { intracellular organelle lumen } \\
\text { (GO: 0070013) }\end{array}$ & 86 & 9.6556 \\
\hline $\begin{array}{l}\text { small ribosomal subunit } \\
\text { (GO: 0015935) }\end{array}$ & 25 & 9.4776 \\
\hline nuclear lumen (GO: 0031981) & 80 & 9.4168 \\
\hline $\begin{array}{l}\text { non-membrane-bounded } \\
\text { organelle (GO: 0043228) }\end{array}$ & 118 & 8.3089 \\
\hline $\begin{array}{l}\text { intracellular non-membrane- } \\
\text { bounded organelle (GO: 0043232) }\end{array}$ & 118 & 8.3089 \\
\hline nuclear part (GO: 0044428) & 84 & 6.6144 \\
\hline $\begin{array}{l}\text { intracellular organelle part } \\
\text { (GO: 0044446) }\end{array}$ & 233 & 5.6180 \\
\hline organelle part (GO: 0044422) & 233 & 5.5031 \\
\hline $\begin{array}{l}\text { vacuolar membrane } \\
\text { (GO: 0005774) }\end{array}$ & 60 & 4.1891 \\
\hline vacuolar part (GO: 0044437) & 60 & 4.0645 \\
\hline cytoplasm (GO: 0005737) & 553 & 4.0376 \\
\hline chloroplast (GO: 0009507) & 140 & 4.0000 \\
\hline cell-cell junction (GO: 0005911) & 75 & 2.2676 \\
\hline plasmodesma (GO: 0009506) & 75 & 2.2676 \\
\hline cell junction (GO: 0030054) & 75 & 2.2676 \\
\hline symplast (GO: 0055044) & 75 & 2.2676 \\
\hline vacuole (GO: 0005773) & 75 & 1.8658 \\
\hline $\begin{array}{l}\text { macromolecular complex } \\
\text { (GO: 0032991) }\end{array}$ & 135 & 1.7261 \\
\hline $\begin{array}{l}\text { cytoplasmic part } \\
\text { (GO: 0044444) }\end{array}$ & 519 & 1.6070 \\
\hline \multicolumn{3}{|l|}{ Molecular function } \\
\hline $\begin{array}{l}\text { structural constituent of } \\
\text { ribosome (GO: 0003735) }\end{array}$ & 66 & 22.5045 \\
\hline
\end{tabular}

Table 2 GO classification of common down-regulated genes in both XT and ZF (Continued)

\begin{tabular}{|c|c|c|}
\hline $\begin{array}{l}\text { structural molecule activity } \\
\text { (GO: 0005198) }\end{array}$ & 70 & 16.4921 \\
\hline $\begin{array}{l}\text { glutamate-cysteine ligase } \\
\text { activity (GO: 0004357) }\end{array}$ & 3 & 1.8413 \\
\hline \multicolumn{3}{|l|}{ Biological process } \\
\hline translation (GO: 0006412) & 80 & 14.2749 \\
\hline gene expression (GO: 0010467) & 125 & 8.8182 \\
\hline $\begin{array}{l}\text { cellular macromolecule biosynthetic } \\
\text { process (GO: 0034645) }\end{array}$ & 112 & 5.7328 \\
\hline $\begin{array}{l}\text { macromolecule biosynthetic } \\
\text { process (GO: 0009059) }\end{array}$ & 112 & 5.3316 \\
\hline $\begin{array}{l}\text { cellular biosynthetic process } \\
\text { (GO: 0044249) }\end{array}$ & 175 & 5.1952 \\
\hline $\begin{array}{l}\text { biosynthetic process } \\
\text { (GO: 0009058) }\end{array}$ & 187 & 4.7235 \\
\hline $\begin{array}{l}\text { organic substance biosynthetic } \\
\text { process (GO: 1901576) }\end{array}$ & 175 & 3.8861 \\
\hline $\begin{array}{l}\text { ribosome biogenesis } \\
\text { (GO: 0042254) }\end{array}$ & 24 & 3.8239 \\
\hline metabolic process (GO: 0042254) & 580 & 2.9788 \\
\hline $\begin{array}{l}\text { ribonucleoprotein complex } \\
\text { biogenesis (GO: 0022613) }\end{array}$ & 26 & 2.5768 \\
\hline $\begin{array}{l}\text { polysaccharide localization } \\
\text { (GO: 0033037) }\end{array}$ & 9 & 2.2790 \\
\hline callose localization (GO: 0052545) & 9 & 2.2790 \\
\hline $\begin{array}{l}\text { sulfur compound metabolic } \\
\text { process (GO: 0006790) }\end{array}$ & 19 & 1.4773 \\
\hline $\begin{array}{l}\text { defense response by callose } \\
\text { deposition (GO: 0052542) }\end{array}$ & 7 & 1.4176 \\
\hline
\end{tabular}

\section{Discussion}

High temperature is an adverse factor influencing both plant growth and development, thereby causing extensive loss of yield [29]. Although the physiological effects of heat stress on crops has been extensively reported, the understanding of underlying molecular mechanism remains limited. In the present study, we found that most of proteins encoded by up-regulated genes were localized in chloroplast and its structural components, and involved in multiple biological processes associated with photosynthesis. Obviously, they are closely related to function of chloroplast, especially photosynthesis, indicating that these chloroplast proteins play an important role in increasing heat tolerance in sweet maize. In contrast, the proteins encoded by 1,261 down-regulated genes were localized in multiple cellular components, including cytoplasm, nuclear, non-membrane-bounded organelle, ribosome, vacuole, chloroplast and plasmodesma, and were involved in a series of biological processes from gene expression to translation, suggesting 

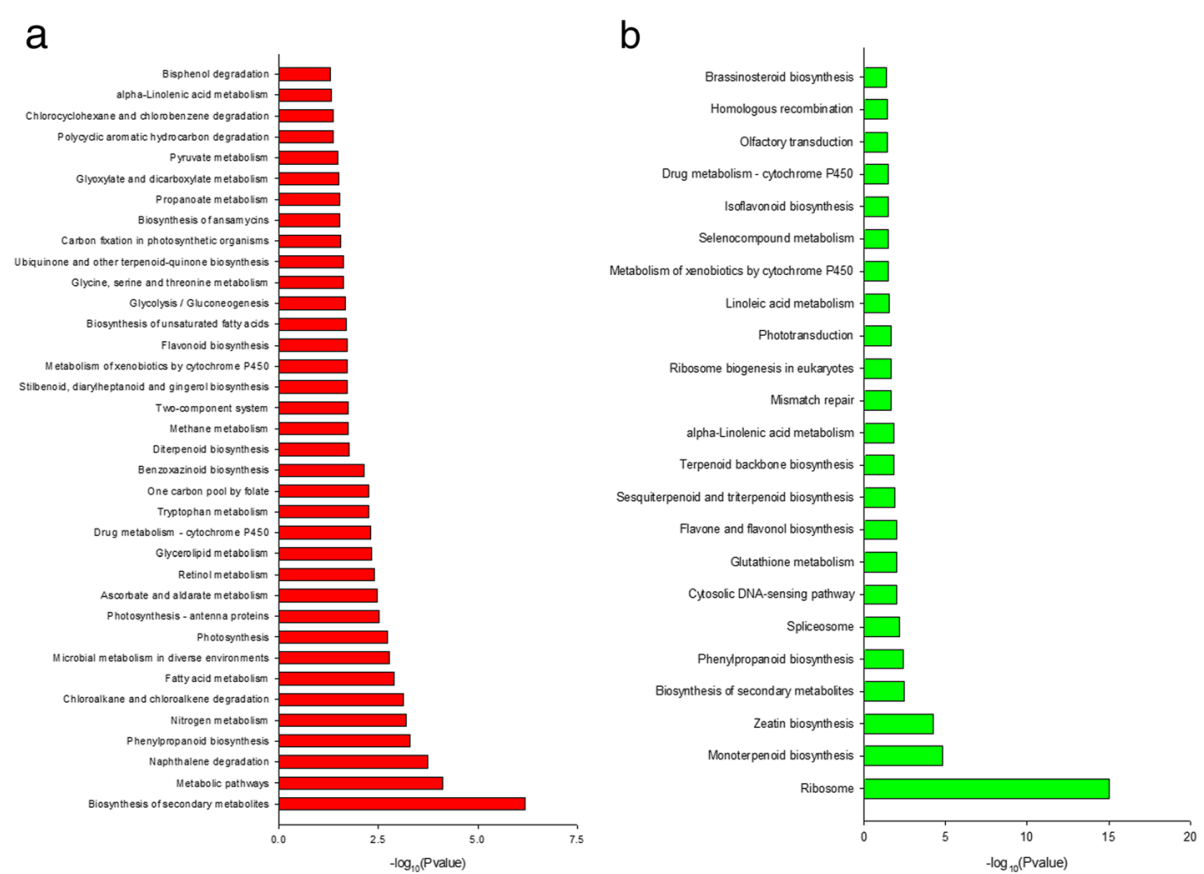

Fig. 3 KEGG pathway enrichment analysis based on the differentially expressed genes. a Pathway enrichment analysis based on the differentially up-regulated genes in both XT and ZF. b Pathway enrichment analysis based on the differentially down-regulated genes in both XT and ZF. XT: Xiantian 5; ZF: Zhefengtian 2
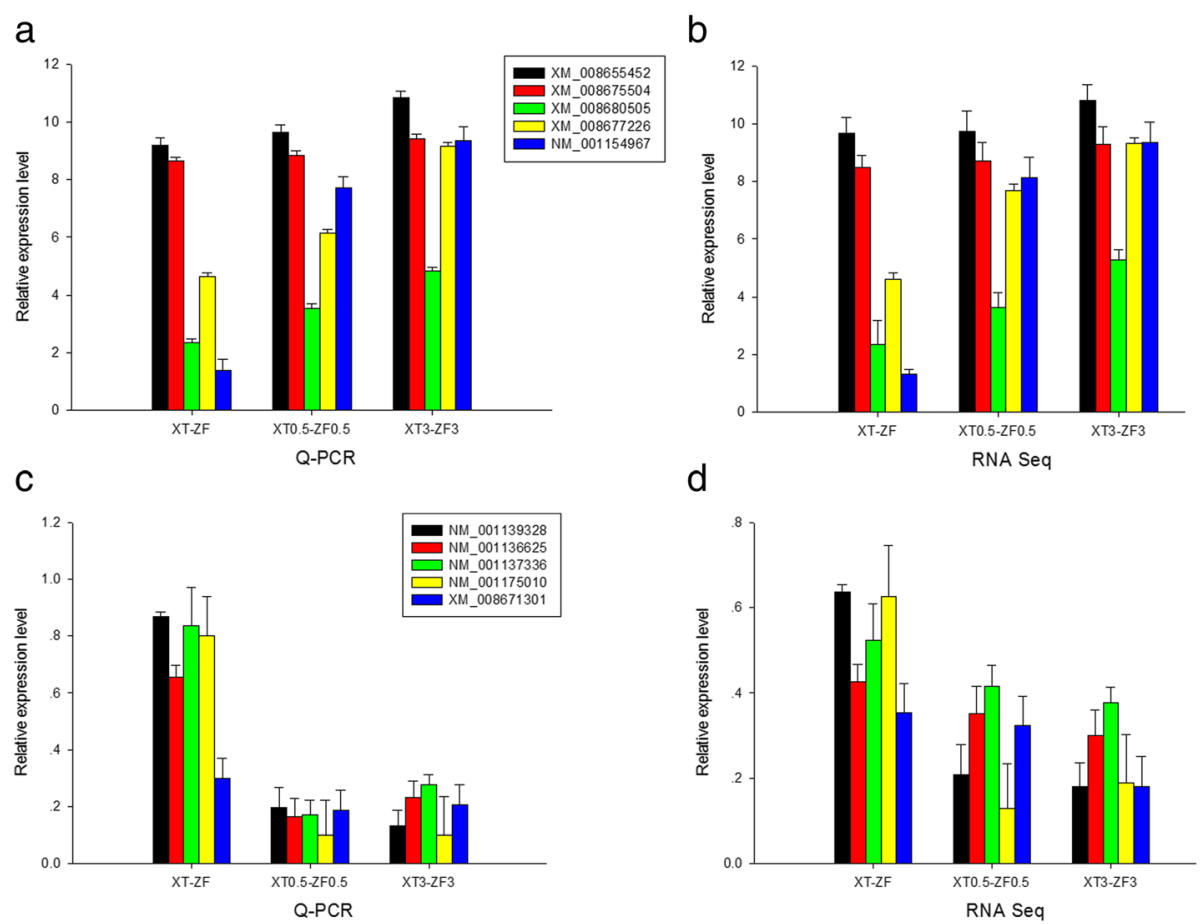

Fig. 4 Validation of differentially expressed candidate genes. a qRT-PCR analysis of five up-regulated genes in response to heat stress in XT and ZF. b Expression of five up-regulated genes in XT and ZF based on RNA-seq data. c qRT-PCR analysis of five down-regulated genes in response to heat stress in XT and ZF. $\mathbf{d}$ Expression of five down-regulated genes in XT and ZF based on RNA-seq data. Three independent experimental replicates were analyzed for each sample, and data were indicated as mean \pm SE $(n=3)$ 
that lowering these processes may contribute to improved heat resistance in sweet maize.

Here, we found there was an apparent connection between the heat tolerance of sweet corn and the alterations in 3 pathways, including the biosynthesis of secondary metabolites, photosynthesis (up-regulation) and ribosome function (down-regulation), which was consistent with the results of previous studies [14, 21]. Apart from the above-mentioned pathways, the differences in 9 pathways including photosynthesis, photosynthesisantenna proteins, stilbenoid, diarylheptanoid and gingerol biosynthesis, flavonoid biosynthesis, diterpenoid biosynthesis, biosynthesis of unsaturated fatty acids, nitrogen metabolism, flavone and flavonol biosynthesis and monoterpenoid biosynthesis, were found between heat-tolerance and heat-sensitive sweet maize cultivars, which also appeared between heat-tolerance and heat-sensitive pepper ones [22], indicating that they might be the most fundamental pathways involved in heat tolerance in other crop species.

Interestingly, both up-regulated and down-regulated genes have been identified to be involved in 5 identical pathways including biosynthesis of secondary metabolites, phenylpropanoid biosynthesis, alpha-Linolenic acid metabolism, metabolism of xenobiotics by cytochrome P450 and drug metabolism- cytochrome P450, indicating that genes involved in these pathways showed patterns of both upregulating and downregulating expression, which was likely to help keep these pathways in balance under heat stress.

Previous studies showed that 7 hormones including ABA, auxin, jasmonic acid (JA), cytokinins (CKs), ethylene, gibberellin, and brassinosteroid were likely to be involved in heat stress [22]. Interestingly, several hormones including ABA, brassinosteroids (BRs), and ethylene possibly interacted through complex networks to regulate heat stress responses [30]. In the present study, we found that some genes related to two plant hormone signal pathways including zeatin biosynthesis and brassinosteroid biosynthesis had lower levels in XT (heat tolerant) than in ZF (heat sensitive), indicating that reduced biosynthesis of zeatin and brassinosteroid was likely to be related to heat tolerance in sweet maize. Accumulating evidences also demonstrated that changes in zeatin content were related to plant heat tolerance. In creeping bentgrass, the levels of various cytokinins, zeatin $(\mathrm{Z})$, zeatin riboside (ZR), dihydrogen zeatin riboside (DHZR) and isopentinyl adenosine (iPA), showed dramatic decline in root and shoot under high soil temperature, which were correlated with decreased dry matter production [31]. In a dwarf wheat variety, high-temperature-induced decrease in cytokinin content was responsible for reduced kernel filling and its dry weight [32]. However, brassinosteroids conferred the basic thermotolerance to tomato and oilseed rape
(Brassica napus), but not to cereals [33]. Therefore, it was suggested that heat-tolerant sweet maize might keep at lower growth level than heat-sensitive one through dowregulating expression of genes related to zeatin and brassinosteroid biosynthesis to better regulate heat stress responses.

\section{Conclusions}

Comparative transcriptome analsis revealed 516 commonly up-regulated and 1,261 commonly down-regulated genes between heat tolerant and heat sensitive sweet maize genotypes under heat stress. Gene Ontology classification and KEGG pathway analysis of these differentially expressed genes showed that secondary metabolite biosynthetic pathway and ribosome were the most significant ones. Further analysis revealed that 9 fundamental pathways, 5 identical pathways and 2 hormonal signal pathways (zeatin and brassinosteroid biosynthesis) were likely to play important roles in regulating the response of maize to heat stress. Therefore, our results provide a new insight into transcriptional alterations in heat-resistant and heat-sensitive sweet maize varieties under heat stress, which helps to address underlying molecular mechanism of maize in response to heat stress.

\section{Methods}

Plant materials, growth conditions and heat treatment

Sweet maize seeds of Xiantian 5 (XT) and Zhefengtian 2 (ZF) were supplied by the Zhejiang Wuwangnong Seed Group Co., Ltd. (Hangzhou, Zhejiang province, China). Four replicates of 50 seeds for each treatment and each genotype were placed in the germination boxes $(18 \mathrm{~cm} \times 13 \mathrm{~cm} \times 10 \mathrm{~cm})$ containing a layer of moistened peat matrix ( $30 \mathrm{~mm}$ in thickness), and then surface covered with a thin layer of peat matrix. The seeds were germinated for 21 days at $25{ }^{\circ} \mathrm{C}$, $90 \%$ relative humidity, and $16 \mathrm{~h}$ light $/ 8 \mathrm{~h}$ dark. The threeweek-old seedlings were treated with $42{ }^{\circ} \mathrm{C}$ for $0.5 \mathrm{~h}$, $3 \mathrm{~h}$, and $6 \mathrm{~h}$, respectively. Maize leaves experiencing $42{ }^{\circ} \mathrm{C}$ heat stress for $0.5 \mathrm{~h}$ or $3 \mathrm{~h}$ were collected and subsequently used for transcriptomic analysis. Maize seedlings receiving $42^{\circ} \mathrm{C}$ treatment for $6 \mathrm{~h}$ were cultivated in a $25^{\circ} \mathrm{C}$ incubator with $90 \%$ relative humidity and $16 \mathrm{~h}$ light $/ 8 \mathrm{~h}$ dark. Mortality of these seedlings were determined 7 days after incubation at $25{ }^{\circ} \mathrm{C}, 90 \%$ relative humidity, and $16 \mathrm{~h}$ light $/ 8 \mathrm{~h}$ dark.

\section{RNA sequencing and data analysis}

Maize leaves from ten plants were pooled as an independent experimental replicate, and the leaves from other ten plants that were treated in the same growth chamber at intervals of three weeks were pooled as another independent experimental replicate. Three independent experimental 
replicates were used for transcriptomic analysis. Total leaf RNA was isolated from maize leaves using Trizol reagent (Invitrogen, USA) according to the manufacturer's protocols, dissolved in RNase-free water and then used to construct transcriptome sequence library using the NEBNext Ultra RNA Library Prep Kits for Illumina (NEB, USA) following the manufacturer's instructions. Index codes were added to attribute sequences to each sample. At last, $125 \mathrm{bp}$ paired-end reads were generated using Illumina HiSeq 2500 (Novogene, China). Clean reads were obtained by removing the reads containing adapter or ploy- $\mathrm{N}$ and the low quality reads from raw data. They were aligned to the B73 maize genome using the TopHat (2.0.9) software. To measure gene expression level, the total number of reads per kilobases per millionreads (RPKM) of each gene was calculated based on the length of this gene and the counts of reads mapped to this gene. RPKM values were calculated based on all the uniquely mapped reads. The genes with RPKM ranging from 0 to 3 were considered at a low expression level; the genes with RPKM ranging from 3 to 15 at a medium expression level; and the genes with RPKM above 15 at a high expression level. Differential expression analysis was calculated using the DESeq $\mathrm{R}$ package (1.10.1). The resulting $p$ values were adjusted using the Benjamini and Hochberg's approach for controlling the false discovery rate. Genes with an adjusted $p$ value $<0.05$ identified by DESeq were assigned as differentially expressed. GO annotation was performed using the Blast2GO software (GO association was done by a BLASTX against the NCBI NR database). GO enrichment analysis of differentially expressed genes was then performed by the BiNGO plugin for Cytoscape. Over-presented GO terms were identified using a hypergeometric test with the significance threshold of 0.05 after the Benjamini and Hochberg FDR correction. KEGG enrichment analysis of differentially expressed genes was performed using the KOBAS (2.0) [34] software.

\section{Verification of RNA-seq data by quantitative real-time PCR (qRT-PCR)}

To test the reliability of RNA-seq data (Additional file 1), a set of top ten up-regulated genes in three replicates were selected for qRT-PCR. Specific primers were designed with the Primer Express software (Applied Biosystems) and synthesized by Sangon (Shanghai, China). cDNA was synthesized from $1 \mu \mathrm{g}$ of total RNA using the PrimeScript RT reagent Kit (Takara, Dalian, China). Real-time RT-PCR was performed on the ABI 7500 Real-Time PCR System (Applied Biosystems) using the $2 \times$ SYBR green PCR master mix (Applied Biosystems). Three independent experimental replicates were analyzed for each sample, and data were indicated as mean $\pm \operatorname{SE}(n=3)$. Eleven pairs of primers were designed for gene-specific transcript amplification (Additional file 2).

\section{Additional files}

Additional file 1: RNA-seq dataset of maize seedlings of different genotypes under heat stress. (XLS $18900 \mathrm{~kb}$ )

Additional file 2: Eleven pairs of primers were designed for gene-specific transcript amplification. (DOC $28 \mathrm{~kb}$ )

\section{Abbreviations \\ ABA: Abscisic acid; BRs: Brassinosteroids; CKs: Cytokinins; DEGs: Differential expression genes; GO: Gene Ontology; HSPs: Heat shock proteins; JA: Jasmonic acid; KEGG: Kyoto Encyclopedia of Genes and Genomes; qRT-PCR: Quantitative real-time PCR; RPKM: Reads per kilobases per millionreads; XT: XIANTIAN 5; ZF: ZHEFENGTIAN 2}

\section{Acknowledgements}

This work was supported by the Project of Financial funds for Agriculture (Grant No.: 201502 to J. S.).

\section{Funding}

1. The Project of Financial funds for Agriculture, Award Number: 201502 | Recipient: Jiang Shi.

2. Great Project of Science and Technology of Hangzhou, Award

Number:20131812A02 | Recipient: Songlin Ruan, Ph.D.

Availability of data and materials

All the data supporting these findings is contained within the manuscript.

\section{Authors' contribution}

JS carried out analysis of RNA sequencing, bioinformatics and Q-PCR. BYY and XPL carried out material preparation and phenotype analysis. HSM and SLR conceived of the study, participated in its design and coordination and completed the manuscript. All authors read and approved the final manuscript.

\section{Competing interests \\ The authors declare no competing interests.}

Consent for publication

Not applicable.

Ethics approval and consent to participate

No ethics approval and consent is required.

\section{Author details}

${ }^{1}$ Institute of Crop Science, Hangzhou Academy of Agricultural Sciences, Hangzhou 310024, People's Republic of China. 'Laboratory of Plant Molecular Biology \& Proteomics, Institute of Biotechnology, Hangzhou Academy of Agricultural Sciences, Hangzhou 310024, People's Republic of China. ${ }^{3}$ Jiande seed management station, Hangzhou 311600, People's Republic of China.

${ }^{4}$ Xianshan Institute of Agricultural Sciences, Hangzhou 330100, People's Republic of China.

Received: 23 September 2016 Accepted: 10 January 2017

Published online: 25 January 2017

References

1. Zhang B, Dong S, Hu C, Wang K. Research progress on heat stress and adaptation of maize. J Weifang Univ. 2006;6(6):90-4.

2. Awasthi $R$, Bhandari $K$, Nayyar $H$. Temperature stress and redox homeostasis in agricultural crops. Front Environ Sci. 2015;3:1-24. doi: 10.3389/fenvs. 2015.00011

3. Karim MA, Fracheboud Y, Stam PP. Effect of high temperature on seedling growth and photosynthesis of tropical maize genotypes. Agron Crop Sci. 2000;184(4):217-23.

4. Zhao F, Li C, Liu T. Effect of high temperature during flowering on photosynthetic characteristics and grain yield and quality of different genotypes of Maize (Zea Mays L.). Scientia Agri Sinica. 2012;45(23):4947-58.

5. Almeselmani M, Deshmukh PS, Sairam RK, Kushwaha SR, Singh TP. Protective role of antioxidant enzymes under high temperature stress. Plant Sci. 2006;171(3):382-8. 
6. Sairam R, Srivastava G, Saxena D. Increased antioxidant activity under elevated temperatures: a mechanism of heat stress tolerance in wheat genotypes. Biol Plant. 2000;43(2):245-51.

7. Hasanuzzaman M, Nahar K, Alam MM, Roychowdhury R, Fujita M Physiological, biochemical, and molecular mechanisms of heat stress tolerance in plants. Inter J Mol Sci. 2013;14(5):9643-84.

8. Rochester DE, Winter JA, Shah DM. The structure and expression of maize genes encoding the major heat shock protein, hsp70. EMBO J. 1986;5(3):451-8

9. Zhang $X$, Rerksiri W, Liu A, Zhou X, Xiong H, Xiang J, Chen X, Xiong X. Transcriptome profile reveals heat response mechanism at molecular and metabolic levels in rice flag leaf. Gene. 2013;530:185-92.

10. Gonzalez-Schain N, Dreni L, Lawas LMF, Galbiati M, Colombo L, Heuer S, Jagadish KSV, Kater MM. Genome-wide transcriptome analysis during anthesis reveals new insights into the molecular basis of heat stress responses in tolerant and sensitive rice varieties. Plant Cell Physiol. 2016:57(1):57-68.

11. Arasakesary SJ, Manonmani S, Pushpam R, Robin S. New temperature sensitive genic male sterile lines with better outcrossing ability for production of two-line hybrid in rice. Rice Sci. 2015;22(1):49-52.

12. Raafat EN, Saber S, Yonnelle DM, Rodomiro O, Baboucarr M. Microsatelliteaided screening for fertility restoration genes $(R f)$ facilitates hybrid improvement. Rice Sci. 2016;23(3):160-4.

13. Frey FP, Urbany C, Hüttel B, Reinhardt R, Stich B. Genome-wide expression profiling and phenotypic evaluation of European maize inbreds at seedling stage in response to heat stress. BMC Genomics. 2015;16:123.

14. Qin D, Wu H, Peng H, Yao Y, Ni Z, Li Z, Zhou C, Sun Q. Heat stressresponsive transcriptome analysis in heat susceptible and tolerant wheat (Triticum aestivum L.) by using wheat genome array. BMC Genomics. 2008;9:432.

15. Mangelsen E, Kilian J, Harter K, Jansson C, Wanke D, Sundberg E. Transcriptome analysis of high-temperature stress in developing barley caryopses: early stress responses and effects on storage compound biosynthesis. Mol Plant. 2011:4(1):97-115.

16. Jin F, Hu L, Yuan D, Xu J, Gao W, He L, Yang X, Zhang X. Comparative transcriptome analysis between somatic embryos (SEs) and zygotic embryos in cotton: evidence for stress response functions in SE development. Plant Biotechnol J. 2014;12(2):161-73.

17. Nigam D, Kavita P. Tripathi R K, Ranjan A, Goel R, Asif M, Shukla A, Singh G, Rana D, Sawant SV: Transcriptome dynamics during fibre development in contrasting genotypes of Gossypium hirsutum L. Plant Biotechnol J. 2014;12(2):204-18.

18. Lee YH, Kim KS, Jang YS, Hwang JH, Lee DH, Choi H. Global gene expression responses to waterlogging in leaves of rape seedlings. Plant Cell Rep. 2014;33(2):289-99.

19. Aulakh SS, Veilleux RE, Dickerman AW, Tang G, Flinn BS. Characterization and RNA-seq analysis of underperformer, an activation-tagged potato mutant. Plant Mol Biol. 2014;84(6):635-58.

20. Wu H, Chen D, Li J, Yu B, Qiao X, Huang H, He Y. De Novo characterization of leaf transcriptome using 454 sequencing and development of EST-SSR markers in Tea (Camellia sinensis). Plant Mol Biol Report. 2013;31(3):524-38.

21. Blanco-Ulate B, Cantu D. Tomato transcriptome and mutant analyses suggest a role for plant stress hormones in the interaction between fruit and Botrytis cinerea. Front Plant Sci. 2013;4(2013):14.

22. Li T, Xu X, Li Y, Wang H, Li Z, Li Z. Comparative transcriptome analysis reveals differential transcription in heat-susceptible and heat-tolerant pepper (Capsicum annum L.) cultivars under heat stress. J Plant Biol. 2015; 58:411-24.

23. Fan M, Huang $Y$, Zhong $Y$, Kong Q, Xie J, Niu M, Xu Y, Bie Z. Comparative transcriptome profiling of potassium starvation responsiveness in two contrasting watermelon genotypes. Planta. 2014;239(2):397-410.

24. Liao D, Cram D, Marsolais F. Transcriptome profiling identifies candidate genes associated with the accumulation of distinct sulfur-glutamyl dipeptides in Phaseolus vulgaris and Vigna mungo seeds. Front Plant Sci. 2013;4:60

25. Fondevilla $S$, Rotter $B$, Krezdorn N, Jüngling $R$, Winter $P$, Rubiales $D$. Identification of genes involved in resistance to didymella pinodes in pea by deepsupersage transcriptome profiling. Plant Mol Biol Report. 2014;32(1):258-69.
26. Singh VK, Garg R, Jain M. A global view of transcriptome dynamics during flower development in chickpea by deep sequencing. Plant Biotechnol J. 2013;11(6):691-701.

27. Ibáeza AM, Martinellia F, Reagana RL, Uratsua SL, Voa A, Tinocoa MA, Phua ML, Chend Y. Rocked, DM, Dandekar AM: Transcriptome and metabolome analysis of Citrus fruit to elucidate puffing disorder. Plant Sci. 2014;217-218:87-98.

28. Fernandes J, Morrow D, Casati P, Walbot V. Distinctive transcriptome responses to adverse environmental conditions in Zea mays L. Plant Biotechnol J. 2008;6(8):782-98.

29. Wahid A, Farooq M, Hussain I, Rasheed R, Galani S. Responses and management of heat stress in plants. In: Ahmad P, Prasad MNV, editors. Environmental adaptations and stress tolerance of plants in the era of climate change. New York: Springer; 2012. p. 135-57.

30. Qu AL, Ding YF, Jiang Q, Zhu C. Molecular mechanisms of the plant heat stress response. Biochem Biophys Res Commun. 2013:432:203-7.

31. Liu X, Huang B. Root physiological factors involved in cool-season grass response to high soil temperature. Environ Experi Bot. 2005;53:233-45.

32. Banowetz GM, Ammar K, Chen DD. Temperature effects on cytokinin accumulation and kernel mass in dwarf wheat. Ann Bot. 1999:83:303-7.

33. Dhaubhadel S, Chaudhary S, Dobinson KF, Krishna P. Treatment with 24epibrassinolide, a brassinosteroid, increases the basic thermotolerance of Brassica napus and tomato seedlings. Plant Mol Biol. 1999:40:333-42.

34. Mao X, Cai T, Olyarchuk JG, Wei L. Automated genome annotation and pathway identification using the KEGG Orthology (KO) as a controlled vocabulary. Bioinformatics. 2005;21:3787-93.

\section{Submit your next manuscript to BioMed Central and we will help you at every step:}

- We accept pre-submission inquiries

- Our selector tool helps you to find the most relevant journal

- We provide round the clock customer support

- Convenient online submission

- Thorough peer review

- Inclusion in PubMed and all major indexing services

- Maximum visibility for your research

Submit your manuscript at www.biomedcentral.com/submit

) Biomed Central 